\title{
Mapeamento de competências profissionais de Tutores de cursos na Modalidade à Distância
}

\section{Mapping the Professional Competences by Tutors in Distance Courses}

\author{
Francisco Antonio Coelho J unior* \\ Universidade de Brasília - UnB, Distrito Federal, Brasília, Brasil
}

\section{Cristiane Faiad**}

Universidade Salgado de Oliveira- UNIVERSO, Niterói, Rio de Janeiro, Brasil

\section{J oão Paulo Fonseca Borges***}

Universidade de Brasília - UnB, Distrito Federal, Brasília, Brasil

\author{
Natália Ferreira da Rocha**** \\ Universidade de Brasília - UnB, Distrito Federal, Brasília, Brasil
}

\begin{abstract}
RESUMO
O presente trabalho, de natureza teórica/empírica, objetiva identificar competências necessárias ao desempenho das atribuições de tutores que atuam em eventos instrucionais ofertados à distância. Quanto ao método, este estudo foi desenvolvido no contexto de cursos a distância ofertados pela Universidade Aberta do Brasil (UAB) na Universidade de Brasília. Os dados foram coletados presencialmente, por meio de entrevistas, individuais e grupais, semi-estruturadas, com tutores. Como procedimentos de análise de dados, procedeu-se à extração das competências profissionais por meio de seus critérios de ocorrência e condições de mensuração utilizando como parâmetros os conhecimentos, habilidades e atitudes associadas. Identificou-se um conjunto de competências técnicas e interpessoais relacionadas ao planejamento/execução do desempenho. Como limitações, verificou-se dificuldades dos participantes em identificarem e nomearem as competências. Sugere-se que as organizações efetivem ações de desenvolvimento profissional e de capacitação, inclusive para seus gestores, no sentido de implementarem uma cultura de apoio e suporte ao desenvolvimento de competências.
\end{abstract}

Palavras-chave: Competências Profissionais, Tutoria, Práticas de Recursos Humanos

\section{ABSTRACT}

This work, theoretical/empirical, aims to identify competencies needed to perform the tasks of tutors who work in instructional events offered entirely at a distance. As to the method, this study was developed in the context of distance learning courses offered by the Open University of Brazil (UAB) in University of Brasília. Data were collected by some interviews, individual and 
group semi-structured interviews with tutors that performed at distance courses. As procedures for data analysis, was proceeded to the extraction of professional skills through their criteria and conditions of occurrence measurement using, as parameters, the knowledge, skills and attitudes associated. It was identified a set of technical and interpersonal skills related to planning/execution performance. As limitations, there are difficulties in identifying the participants and nominate skills. It is suggested that organizations effective action for professional development and training, including their managers, to implement a culture of support his skills development.

Keywords: Professionals Competences, Tutoring, Human Resource Management.

\section{I ntrodução}

A literatura sobre comportamento organizacional vem destacando que a utilização de estratégias voltadas à aquisição e expressão de competências em situação de trabalho tem se mostrado um importante diferencial na busca pela otimização dos desempenhos humano e organizacional. Torna-se, assim, de fundamental valia desenvolver, de forma científica, métodos e técnicas necessárias ao aprimoramento da gestão por competências, em especial à fase de mapeamento, como forma de agregar valor ao negócio da organização. Considera-se que a fase de mapeamento de competências é fundamental posto que nela identificam-se prérequisitos necessários ao desempenho competente de determinada atribuição.

Para fins de realização do presente trabalho adotar-se-á o pressuposto teórico de que competências implicam na capacidade para agir a partir da mobilização de saberes em torno do alcance de resultados esperados. Compreende-se aqui, segundo discussão apresentada por Melo e Paiva (2008), que os termos qualificação e competências são interdependentes e relacionados, posto que a manifestação destas implica na capacidade de entrega por parte dos indivíduos a partir de condições dadas em seu posto de trabalho ou de ocupação.

A literatura nos campos de saber da administração e da psicologia organizacional e do trabalho ressalta que o estudo sobre competências aplicado ao cenário organizacional deve ser de caráter sistêmico, e deve possibilitar que os gestores tenham informações válidas voltadas ao acompanhamento, monitoramento e supervisão das expressões destas competências em desempenho por parte de seus funcionários. Para Bahry e Tolfo (2004) competências mapeadas possibilitam constante monitoramento e revisão de processos organizacionais, tendo, portanto, grande aplicação prática por parte dos gestores organizacionais. Afirmam, ainda, na linha de 
Le Boterf (2003) e Santos, Coelho Jr. e Faiad (2011), que se trata de um conceito em construção.

O conceito de competência, em linhas gerais, refere-se a uma característica subjacente a uma pessoa que é relacionada com desempenho superior na realização de uma tarefa ou em determinada situação. Para fins de compreensão deste Artigo competência é entendida não apenas como um conjunto de conhecimentos, habilidades e atitudes necessários para exercer certa atividade, mas, também, como o desempenho expresso pela pessoa em determinado contexto, em termos de comportamentos adotados no trabalho e realizações decorrentes da mobilização de repertório que cada indivíduo retém. Competência, portanto, é facilitadora do desempenho no trabalho.

A implementação da gestão por competências é feita gradualmente, por meio de etapas. Uma das delas, o mapeamento, que é objeto central deste trabalho, é de fundamental valia ao provimento de informações e insumos que serão posteriormente utilizados na efetivação da gestão. Como efetuar este diagnóstico, ou quais estratégias e técnicas utilizar, ainda são considerados pontos mais importantes verificados na literatura de comportamento organizacional, dada a diversidade de ferramentas e métodos que estão em contínua profusão prática nas organizações. Contudo, apesar de muito difundidos e utilizados pelas organizações em geral, os mesmos carecem, ainda, de comprovação em termos de sua validade ou sistematicidade cientifica, identificando-se, assim, quais procedimentos são válidos àquilo que se propõem por serem mais precisos na ação do mapeamento de competências.

Assim, o objetivo deste trabalho, de natureza teórico/empírica, consiste em relatar o mapeamento de competências profissionais realizado com atores sociais que atuam em cursos ofertados na modalidade à distância. Mais especificamente, o foco deste trabalho consiste na identificação de competências profissionais de tutores que atuam à distância.

Os atores sociais de curso à distância, como tutores, designers instrucionais, apoio logístico e acadêmico, dentre outros envolvidos na oferta desta modalidade de atuação, vêm sendo bastante requeridos por parte das organizações, especialmente em virtude do advento e consolidação das novas tecnologias da informação e de comunicação aplicadas à realidade empresarial. Justifica-se a realização deste trabalho quando se considera que diversas organizações vêem investindo fortemente no desenvolvimento de sistemas instrucionais, e que o pleno êxito destes cursos passa pelo grau de expertise dos atores sociais envolvidos nos mesmos, por excelência os tutores, responsáveis pelo suporte provido à aprendizagem dos treinandos. 
Diversos sistemas administrativos, subsistemas de atuação ou mesmo eventos de capacitação (treinamento) já passam a ser ofertados à distância. Logo, o estudo científico dessa modalidade, em termos de suas variáveis antecedentes, bem como a compreensão das variáveis relacionadas ao desempenho competente de um indivíduo, são de fundamental valia ao êxito no empreendimento destas ações. Por isso, justifica-se a relevância em se mapear competências funcionais desta classe de atores sociais (tutores), permitindo, assim, que se logre êxito no empreendimento das ações educacionais e que se justifique os altos valores de investimentos direcionados ao planejamento de cursos à distância.

Especificamente, serão descritos os passos e procedimentos metodológicos que foram adotados para a extração das competências profissionais, culminando com o seu mapeamento. As competências mapeadas também serão apresentadas, esperando-se que, desta forma, em termos de implicações práticas, as organizações, em geral, tenham um parâmetro inicial acerca dos pré-requisitos em termos de conhecimentos, habilidades e atitudes que são necessários ao desempenho competente dos tutores que atuam na modalidade de educação à distância.

Quanto a implicações teóricas, o presente artigo apresenta contribuição para os estudos organizacionais e para a área de gestão de pessoas, visto que pouca publicação empírica é disponibilizada na literatura nacional sobre o tema de mapeamento de competências, ainda mais aplicada à realidade do ensino à distância.

\section{Fundamentação teórica}

O estudo sobre competências tem despertado o interesse de teóricos e profissionais oriundos de distintos campos de saber. $\mathrm{Na}$ área de comportamento organizacional, foco central de discussão neste artigo, verifica-se que tal constatação também pode ser corroborada. Diversos relatos teóricos e/ou empíricos podem ser obtidos em publicações científicas especializadas, especialmente na literatura nacional, como pode ser observado em Barbosa e Rodrigues (2005), promovendo, assim, uma grande diversidade de teorias e definições associadas ao termo competência, quando aplicado ao contexto das organizações formais de trabalho. Tal constatação gera o levantamento de uma série de questões relativas à definição e à sistematização deste termo. Esta constatação teórica se justifica pela grande infinidade de termos e definições associadas a este conceito, encontrada nos estudos organizacionais, de gestão de pessoas e na área de comportamento organizacional (Paiva \& Melo, 2008).

O conceito de competência é multi-determinado e de natureza plural (Brandão \& Borges-Andrade, 2007; Dutra, 2004). A maior dificuldade 
associada à delimitação do mesmo reside na atribuição de parâmetros precisos e fidedignos de mensuração que permitam à competência ser verificável e avaliável (Brandão \& Borges-Andrade, 2007), ou que tornem aquela competência ou aquela família de competências alinhadas às atribuições e responsabilidades desempenhadas por indivíduos e equipes, ao mesmo tempo em que coadunando tais parâmetros com metas e objetivos estratégicos mais amplos. Para Brandão e Borges-Andrade (2007), a competência é entendida não apenas como um conjunto de conhecimentos, habilidades e atitudes necessários para exercer certa atividade, mas, também, como o desempenho expresso pela pessoa em determinado contexto, em termos de comportamentos adotados no trabalho e realizações decorrentes.

A competência enquanto produto deve ser passível de observação, verificação e análise, ou seja, deve ser expressa em termos de resultado tangível, até mesmo com o objetivo de se obter feedback sobre as práticas adotadas de gestão de pessoas. Já segundo Fleury e Fleury (2001), a noção de competência aparece associada a verbos de ação menos verificáveis empiricamente, como, por exemplo, saber agir, mobilizar recursos, integrar saberes múltiplos e complexos, saber aprender, saber engajar-se, assumir responsabilidades e ter visão estratégica.

O mapeamento de competências deve ser capaz de indicar ou listar quais conhecimentos, habilidades e atitudes que, em complexa interação como um todo, são necessários a cada atribuição designada ao profissional. Mais do que uma competência isolada, resta ao profissional identificar situações, a partir do reconhecimento de sua ambiência, em que ele consiga aplicar, de maneira eficiente, a competência mais condizente ao bom desempenho de cada função de seu cargo. Uma competência não pode ser mapeada como se fosse dissociada das demais, posto que as mesmas se interrelacionam e podem, inclusive, ser facilitadoras de sua expressão nas rotinas de trabalho.

O objetivo do mapeamento de competências relatado neste trabalho consiste em identificar e descrever as competências profissionais (técnicas e comportamentais) necessárias ao desempenho competente de um determinado papel ocupacional. As competências técnicas compreendem os conhecimentos e habilidades diretamente relacionadas ou proximais ao conjunto de atribuições e responsabilidades de um cargo ou função. As competências comportamentais referem-se a atitudes e habilidades mais distais ao cargo, mas compatíveis com as atribuições que devem ser desempenhadas. A partir do mapeamento das competências, seguese para a etapa da modelagem dos perfis de competências, que se refere à construção do perfil composto pelo conjunto de competências necessárias a determinado cargo. Uma vez traçado esse perfil, torna- 
se possível estabelecer critérios, procedimentos e instrumentos que irão compor uma determinada seleção de pessoal, por exemplo, ou servir como insumo para outras ações da área de gestão de pessoas, como treinamento e desenvolvimento de pessoal.

O critério mais importante para o desempenho de uma competência refere-se à sua finalidade ou uso (Guimarães, Bruno-Faria \& Brandão, 2006). Para que servem tais competências no desempenho específico de uma determinada função? Que tipo de competência é mais ou menos requisitada, e para que tipo de atribuição? Respostas possíveis a estas questões passam pela compreensão do conceito de competências. Uma competência refere-se a uma integração entre o saber desempenhar uma tarefa, o querer desempenhá-la e o poder desempenhá-la, na qual a análise de fatores situacionais é de fundamental valia à sua aplicação no trabalho. Conhecimento e tarefa relacionam-se ao formar o conceito de competência e devem ser capazes de prover um desempenho superior no trabalho.

A mobilização de recursos e a utilização estratégica de saberes complexos também são características do conceito de competência (Brandão, 2007). Uma competência deve ser capaz de agregar valor ao indivíduo e à organização, de modo que o principal ativo intangível das organizações modernas, o capital intelectual, deve ser continuamente desenvolvido no âmbito das empresas.

O estabelecimento de objetivos compartilhados, com foco na aprendizagem em grupo e trabalho em equipe são ações gerenciais capazes de estimular a interação social entre os indivíduos e equipes e, assim, prover o desenvolvimento de competências relacionadas ao trabalho. Muito do que a literatura sobre competências apresenta refere-se à capacidade de realização, ou o quanto cada competência é capaz de impactar na consecução de alguma tarefa ou atribuição determinada. Competência, ainda, é compreendida como a capacidade de entrega de um produto, em que o indivíduo deve ser capaz de mobilizar recursos próprios, particularizados em conhecimentos, habilidades e atitudes, em complexa interrelação, voltado ao alcance de um objetivo especifico.

Segundo Santos, Coelho Jr. e Moura (2011), no que se refere a competências individuais, desde os anos 1970, estudos de McClelland (1973), Boyatsis (1982) e Spencer Jr. e Spencer (1993) buscaram enfatizar, de forma mais profunda, as características necessárias ao desempenho humano sob o ponto de vista de conhecimentos, habilidades e atitudes. Estes autores interpretaram a competência como um estoque de qualificações que tornariam a pessoa apta ou capaz de exercer determinado trabalho, sendo um fator de diferenciação entre o desempenho competente e o mau desempenho no trabalho. O termo competência passaria, então, a ser apropriado pela área de recursos humanos e/ou de gestão de pessoas nas 
organizações, como importante insumo para o estabelecimento de práticas e políticas de atuação.

Em termos de produção científica sobre competências nos periódicos da área de administração, Santos et al (2011), analisando seu estado da arte, afirmam, ainda, que a variável competência foi operacionalizada, em sua grande maioria, por meio de artigos de natureza teórico/empírica, usualmente investigados por meio de estudos de caso com a aplicação de técnicas de entrevista comportamental junto a ocupantes de um determinado cargo ou função. Quanto à natureza da pesquisa atualmente realizada nos níveis "micro", "meso" e "macro" do comportamento organizacional, verificou-se bastante diversidade sobre o nível de análise em que o construto competência fora operacionalizado e investigado, ora tido como um atributo humano, ora associado a aspectos típicos de uma organização, como no desenvolvimento de competências organizacionais. Para fins de realização deste trabalho, será dado um enfoque individuai, portanto, micro, ao recorte fenomenológico desta variável.

\section{Método}

\subsection{Descrição da Organização de Estudo}

Este trabalho foi realizado no contexto da Universidade Aberta do Brasil, no âmbito da Universidade de Brasília. Optou-se por seu estudo em virtude de a mesma ofertar uma considerável diversidade de cursos, dentre eles música, administração pública, educação física e especialização em gestão pública, na modalidade à distância, possuindo, assim, um importante grau de expertise na formação de atores sociais envolvidos com este tipo de ensino (a distância), tão cheio de peculiaridades ou idiossincrasias.

A Universidade Aberta do Brasil (UAB) é um sistema consolidado por universidades públicas, que oferece cursos de nível superior para a comunidade, principalmente a camadas da população que têm dificuldades de acesso à formação universitária, por meio do uso da metodologia da educação à distância. O Sistema UAB foi instituído pelo Decreto 5.800, de 08 de junho de 2006, orientado para 0 desenvolvimento da modalidade de educação à distância com a finalidade de expandir e interiorizar a oferta de cursos e programas de educação superior no País.

No âmbito da Universidade de Brasília a UAB está ofertando, atualmente, 9 cursos de graduação e 5 cursos de especialização. Este estudo foi realizado no lócus do curso de bacharelado em administração pública dado à acessibilidade por parte da equipe de pesquisa. 


\subsection{Descrição dos participantes}

O foco deste trabalho consistiu no mapeamento de competências técnicas, diretamente relacionadas ao exercício profissional das tarefas e atribuições, e competências comportamentais, relacionadas às formas pelas quais os indivíduos agem, se relacionam socialmente e interagem entre si, de tutores que atuam na modalidade de ensino a distância. Somente os tutores que atuam no curso de bacharelado em administração pública foram pesquisados.

Optou-se pelo estudo desta categoria de ator social, tutores, por considerar-se que a mesma é essencial e tática ao planejamento e execução de qualquer curso ou treinamento na modalidade à distância, dentro ou fora do contexto de uma organização de trabalho. Sua participação efetiva, portanto, é condição sine qua non para o impacto das ações aprendizes realizadas à distância. Além disso, ressalta-se, o enfoque dado se deveu à acessibilidade aos participantes deste estudo.

Foram realizadas, ao todo, 24 entrevistas semi-estruturadas com professores tutores, com a finalidade de realizar o levantamento das competências profissionais julgadas necessárias para a execução de suas funções, e, assim, proceder com o mapeamento dessas competências. Os procedimentos adotados para a realização destas entrevistas serão descritos adiante.

Quanto aos participantes do estudo, as idades variaram entre 22 a 59 anos, tendo a maioria deles, $65 \%$, a idade de 34,1 anos. $45 \%$ dos participantes eram do sexo masculino. Estes participantes possuíam, pelo menos, diploma de Especialização, o que Ihes permitia desempenhar a função de tutoria. Quando da coleta de dados estes participantes já haviam sido submetidos a treinamento para exercer a função de tutores no curso de bacharelado em administração pública. Os mesmos foram informados sobre os objetivos de pesquisa concordando em participarem da mesma.

\subsection{Descrição do Instrumento de Pesquisa}

As entrevistas foram realizadas por meio da aplicação de um roteiro semi-estruturado. As questões do roteiro foram elaboradas com base tanto na literatura da sobre competências quanto nos objetivos científicos desta pesquisa. Ao todo, foram elaboradas 14 questões de pesquisa (por ser semi-estruturado, não houve um número fixo de questões, isso variou de entrevista para entrevista), em que o pesquisador procurava identificar as principais atribuições dos respondentes, bem como as competências técnicas e comportamentais que deveriam possuir para desempenhar, de forma eficaz, suas funções. Procurou-se identificar as habilidades e 
conhecimentos necessários à consecução das tarefas, além de ter sido solicitado a cada entrevistado(a) que o(a) mesmo(a) relatasse incidente(s) crítico(s) ou dificuldade(s) que ele(a) enfrentou no desempenho das funções e o que ele(a) fez para a resolução da(s) mesma(s). Objetivou-se identificar como os indivíduos mobilizavam o seu repertório de competências no enfrentamento do dia-a-dia de seu trabalho.

Este roteiro semi-estruturado foi previamente validado com três professores do Departamento ao qual a equipe de pesquisa encontrase vinculada, que lecionam tanto na modalidade de ensino presencial quanto a distância, e dois tutores que atuavam, à época, apenas na modalidade a distância. Todos os participantes da pesquisa também foram informados sobre os objetivos deste trabalho e possuíam consentimento livre e esclarecido sobre sua participação, espontânea.

\section{Procedimentos de Coleta e Análise de Dados}

Foram realizados dois tipos de coleta de dados, por meio da aplicação individual de roteiro de entrevista e por meio de grupos focais. O local das entrevistas foi variado, desde o ambiente de trabalho dos tutores até a sala individualizada do professor coordenador responsável pela pesquisa.

Os dois grupos focais foram realizados em uma sala de reuniões. 0 primeiro grupo focal contou com a participação de sete tutores, o segundo, nove. Cada um dos grupos foi coordenado pelo professor responsável pela pesquisa. Os grupos focais levaram, em média, uma hora para serem realizados, e as respostas foram digitadas pela equipe de pesquisa à medida que as questões eram respondidas.

As entrevistas individuais levaram cerca de 10 a 20 minutos, com as respostas sendo gravadas e, logo após o término de cada encontro, transcritas pela equipe de pesquisa. A coleta de dados ocorreu entre os meses de agosto a novembro do ano de 2010.

Os participantes das entrevistas e grupos foram escolhidos pela área de atuação e natureza das funções que desempenhavam, logo, foram entrevistados participantes que exerciam há, pelo menos, 6 meses, a função de tutor. Importante frisar que, por ser um estudo exploratório, voltado ao mapeamento de competências da função de tutor, houve a necessidade de entrevistar o maior número possível de pessoas, considerando sua disponibilidade e mesmo seu interesse em participar deste trabalho.

Os dados obtidos nas entrevistas foram interpretados por meio de análise de conteúdo, utilizando técnicas de Bardin (2009), por meio de análise temática e categorial. Procederam-se à identificação de categorias de tarefas típicas dos tutores, bem como os conhecimentos, habilidades e atitudes necessárias ao pleno 
desempenho das mesmas. As informações foram tratadas de forma sigilosa e anônima, e os indivíduos foram informados previamente de que as entrevistas, individuais ou em grupo, seriam gravadas, para uso específico desta pesquisa.

A análise de conteúdo possibilitou a extração de informações que levaram ao mapeamento das competências técnicas e comportamentais esperadas no desempenho competente da função de tutoria para indivíduos que atuam na modalidade à distância. Utilizaram-se, para tal, as recomendações propostas por Fleury e Fleury (2001) e Brandão e Bahry (2005), para identificação e construção de competências. As principais atribuições também foram identificadas. Estas competências e atribuições associadas serão descritas a seguir.

\section{Resultados}

As competências dos tutores podem ser vinculadas, basicamente, ao grau de relacionamento com os demais atores sociais envolvidos na oferta do curso, como alunos e coordenação de curso, bem como ao seu grau de expertise necessário ao uso do ambiente virtual de aprendizagem (AVA). A excelência no uso das novas tecnologias de comunicação e de informação também é transversal a todas as atribuições mapeadas, assim como a aplicação de ferramentas e técnicas pedagógicas à efetividade da aprendizagem dos alunos, aliada ao planejamento instrucional previamente elaborado.

A Tabela 1 exemplifica competências de natureza técnica e comportamental que foram mapeadas tanto a partir das entrevistas individuais quanto dos grupos focais realizados. Para fins de compreensão, as competências técnicas foram segmentadas em dois tipos: cognitivas, em que foram identificados tipos de conhecimentos e habilidades essenciais à organização e planejamento do trabalho do tutor, além de requisitos pessoais básicos esperados em sua atuação, e funcionais, em que foram consideradas, a partir das tarefas listadas, competências relativas à construção da prática pedagógica do tutor para com seus alunos, numa visão interacional. Habilidades mais proximais à atuação do tutor também foram consideradas como competências técnicas.

Já as competências atitudinais correspondiam a habilidades mais distais à atuação do tutor, relativas à capacidade de motivar os alunos, bem como de planejamento e organização de sua atuação. Foram consideradas, também, atitudes relativas à postura ética e profissional bem como ao desenvolvimento do senso crítico por parte dos Estudantes. 
Francisco Antonio Coelho J unior, Cristiane Faiad, J oão Paulo Fonseca Borges, Natália Ferreira da Rocha Mapeamento de competências profissionais de Tutores de cursos na Modalidade à Distância

\begin{tabular}{|c|c|}
\hline Dimensão/Natureza da Competência & Descrição da Competência \\
\hline Técnica/Cognitiva & $\begin{array}{l}\text { Tenho capacidade de buscar, na literatura, a } \\
\text { teoria relacionada à Disciplina, habilitando-me a } \\
\text { pesquisar e responder eventuais dúvidas de } \\
\text { alunos com presteza e agilidade; } \\
\text { Demonstro domínio do conteúdo a ser } \\
\text { ministrado, visando a melhor responder as } \\
\text { dúvidas e questionamentos dos alunos; } \\
\text { Escrevo respostas de maneira clara e objetiva, } \\
\text { de modo a não gerar ambigüidades e erros de } \\
\text { interpretação por parte do aluno; } \\
\text { Demonstro capacidade de construir, } \\
\text { conjuntamente com o aluno, associações entre } \\
\text { a teoria e a prática, citando exemplos que } \\
\text { facilitem a compreensão por parte do aluno }\end{array}$ \\
\hline Técnica/Funcional & $\begin{array}{l}\text { Identifico respostas iguais ou semelhantes entre } \\
\text { os alunos no ambiente virtual de aprendizagem, } \\
\text { não permitindo que aconteçam cópias de ideias } \\
\text { entre eles ou mesmo plágios; } \\
\text { Intervenho nos fóruns de maneira ativa, } \\
\text { fornecendo novos questionamentos e } \\
\text { observações para que a discussão se mantenha } \\
\text { interessante aos alunos e, assim, para que os } \\
\text { motive a participar; } \\
\text { Tenho capacidade de demonstrar, ao aluno, a } \\
\text { relevância da Disciplina para a sua formação, } \\
\text { de modo a motivá-lo e a torná-lo mais } \\
\text { interessado no conteúdo, evitando sua evasão; } \\
\text { Capacidade de análise e síntese (examino uma } \\
\text { situação, fato ou problema, demonstrando } \\
\text { capacidade de interpretação e processamento } \\
\text { de grande volume de informações, } \\
\text { hierarquizando-as e concatenando-as) }\end{array}$ \\
\hline Comportamental/Atitudinal & $\begin{array}{l}\text { Demonstro flexibilidade e interesse com as } \\
\text { respostas dos alunos; } \\
\text { Capacidade de agir com versatilidade (ajusto- } \\
\text { me a novas situações, adaptando-me a várias } \\
\text { circunstâncias); } \\
\text { Capacidade de agir com senso crítico } \\
\text { (demonstro comportamentos de questionamento } \\
\text { e postura crítica frente à determinada situação } \\
\text { ou evento); } \\
\text { Capacidade de ter visão prática (ajo com base } \\
\text { na realidade concreta do aluno, identificando a } \\
\text { utilidade prática dos conhecimentos estudados } \\
\text { a partir da análise da situação). }\end{array}$ \\
\hline
\end{tabular}

Quanto às suas principais atribuições, cabe ao tutor fomentar a discussão dos conteúdos propostos, participando de fóruns e outras atividades relacionadas à aprendizagem dos alunos, além de tratar os alunos com cordialidade, provendo feedback às suas questões em 
tempo hábil, informando-lhe sobre seu desempenho de forma contínua. Espera-se, ainda, que o tutor provenha à coordenação do curso informações sobre o desempenho dos alunos e sobre 0 andamento da Disciplina como um todo, e atue no sentido de evitar que o aluno evada do curso.

São competências técnicas associadas à sua atuação operar o ambiente virtual de aprendizagem (AVA), demonstrando conhecimento de suas ferramentas, visando a promover a aprendizagem dos alunos, e lançar mão de formas ou estratégias alternativas de ensino, contornando eventuais falhas ou limitações impostas pelo AVA. Outra competência técnica, de natureza funcional, fundamental à sua ação refere-se a responder a eventuais dúvidas e/ou questionamentos do aluno de maneira célere e individualizada, mesmo que não saiba a resposta, avisando que irá buscar encontrar a solução do questionamento, de modo a não deixálo com a sensação de que sua pergunta foi ignorada. É esperado que uma condição de execução desta competência implique no fator temporal, em que o prazo máximo de resposta deva ser limitado a até 48 horas, contados a partir das solicitações dos alunos.

Outra competência técnica de natureza cognitiva específica da atuação do tutor na modalidade de ensino a distância diz respeito a ter o conhecimento ou domínio, na literatura, dos conteúdos e das teorias relacionadas à Disciplina, habilitando-se a pesquisar e responder eventuais dúvidas de alunos com presteza, rapidez e agilidade. Associada a esta competência tem-se, ainda, a capacidade de utilizar exemplos da vida prática, de modo que os alunos passem a ser capazes de formular os próprios exemplos e, assim, que se sintam motivados, demonstrando conhecimento de técnicas pedagógicas, com vistas ao desenvolvimento de estratégias de ensino individualizadas às necessidades dos alunos. Neste sentido, faz necessário que o tutor planeje e execute estratégias de motivação do aluno, provendo feedbacks (negativos e/ou positivos) a todas as respostas de exercícios, chats e fóruns de discussão.

Algumas competências podem ser derivadas da interação do tutor com o AVA (importante ressaltar que cada organização adota um ambiente virtual específico ao tipo de treinamento que será ofertado, segundo suas características e particularidades instrucionais). Tais competências dizem respeito à identificação, nos fóruns de debates, de alunos pouco participativos, visando a procurá-los e trazê-los efetivamente para a discussão. Neste processo está a capacidade do tutor de monitorar a participação dos alunos no AVA, identificando aqueles que participam menos e estimulando-os ao debate. É importante, assim, que o tutor acesse o ambiente de aprendizagem diariamente, não deixando que discussões sejam interrompidas por falta de respostas ou que dúvidas fiquem sem respostas. 
A comunicação é a principal via de interação entre tutor e demais atores sociais envolvidos na modalidade de ensino a distancia. Assim, é importante que o mesmo se comunique, por escrito e verbalmente, de maneira clara, educada e objetiva, evitando maus entendimentos, erros de interpretação e de compreensão. É imprescindível, também, expressar-se por escrito atendendo à norma culta da Língua Portuguesa, de modo que o aluno não perceba erros em suas ponderações. É recomendável, em alguns casos, que o tutor faça uso de outros canais de comunicação com os alunos além do AVA, como telefones e e-mails particulares, de modo a expandir sua acessibilidade e, assim, facilitar o processo de interação e motivação do aluno. Competências associadas a estas dizem respeito à capacidade de construir, conjuntamente com o aluno, associações entre a teoria e a prática, citando exemplos que facilitem a compreensão por parte do aluno, e demonstrar capacidade de análise e síntese, de modo a resumir grandes apostilas em poucos parágrafos de discussão sem que haja perda de conteúdo.

Outras competências mapeadas referem-se ao papel do tutor na aprendizagem dos alunos, especialmente em termos de comportamentos manifestados por estes. Tais competências referemse à capacidade de identificar respostas iguais ou semelhantes entre os alunos no ambiente virtual de aprendizagem, não permitindo que aconteçam cópias de ideias entre eles ou mesmo plágios. Cabe ao tutor intervir nos fóruns de maneira ativa, fornecendo novos questionamentos e observações para que a discussão se mantenha interessante aos alunos e, assim, para que os motive a participar. Para tal espera-se que o tutor manifeste, também, a competência de buscar, continuamente, conhecimento sobre a literatura relacionada à Disciplina, indicando, aos alunos, leituras complementares. Para tal, é necessário qualificar-se em cursos de reciclagem, de modo que o processo de ensino não se torne monótono, engessado, enfadonho e/ou repetitivo.

Quanto ao controle e gerenciamento de sua atividade, é esperado que o tutor efetue o controle formal de notas e demais atividades avaliativas dos alunos, demonstrando capacidade de planejamento e de organização, evitando erros de registro. Além disso, espera-se que ele crie novas oportunidades de aprendizagens para os alunos com desempenho insatisfatório, para que todos consigam aprender, efetivamente, o que foi ensinado. Outra competência associada diz respeito à necessidade de analisar e utilizar os resultados das avaliações para diagnosticar os níveis de aprendizagem dos alunos, avaliando a eficácia do ensino e implementando intervenções pedagógicas quando necessário.

No que se refere às competências comportamentais mapeadas à atuação dos tutores, verificou-se que os mesmos devem atuar com dinamismo e proatividade, demonstrando flexibilidade quanto a 
exigências de cumprimento de prazos e tarefas. Desenvolver o controle emocional e a capacidade de manejo de estresse também são competências imprescindíveis à atuação desta categoria de atores sociais.

Especificamente, espera-se que 0 tutor atue demonstrando capacidade de agir com responsabilidade (agir segundo a conduta profissional esperada, cumprindo prazos, obrigações, normas e regulamentos) e de organização (antever, planejar e ordenar atividades; utilizar o tempo e o espaço de forma adequada, priorizando ações e recursos materiais, financeiros, humanos, dentre outros). É preciso que o tutor tenha capacidade de agir com empatia (colocar-se no lugar do outro, compreendendo seus sentimentos, percepções e crenças) e tenha capacidade de agir com inteligência emocional, ou seja, utilizar as emoções e sentimentos de maneira eficiente na resolução de novos problemas e na determinação de padrões de comportamento, demonstrando controle intencional das emoções, quando em situações adversas ou conflitantes.

Outras competências comportamentais dizem respeito à capacidade de agir com civilidade, sendo polido e cortês ao desempenhar suas atribuições, tratando o outro com educação e respeito. Faz-se mister demonstrar capacidade de raciocínio verbal, ou seja, expressar-se com clareza e precisão, transmitindo ideias ou fatos por meio da linguagem verbal e escrita, demonstrando fluência verbal e escrita. Espera-se, ainda, que o tutor aja com respeito à diversidade, adotando práticas inclusivas e éticas no relacionamento com os alunos, contribuindo para o alcance de sua aprendizagem.

\section{Considerações finais}

O presente trabalho, de natureza teórico/empírica, objetivou mapear competências técnicas e comportamentais necessárias ao desempenho competente da função de tutor que atua na modalidade à distância. Para tal, efetuou-se análise de conteúdo das respostas oriundas de entrevistas individuais e de grupos focais realizados com tutores e profissionais envolvidos em cursos a distância. Para isso, as atribuições e responsabilidades desta função foram identificadas, assim como as competências técnicas ou funcionais e comportamentais, que foram relacionadas à busca pelos melhores resultados e desempenho superior em sua área de atuação.

Isto posto, considera-se que o objetivo da pesquisa foi plenamente atingido, visto que a identificação e mapeamento das competências técnicas e comportamentais foi realizado. Os conhecimentos e as habilidades necessários ao desempenho eficaz de cada competência, relacionados à presença de uma condição e de um critério de verificação de sua expressão, também foram identificados. Tais 
competências mapeadas, inclusive, correspondem ao que comumente a literatura em comportamento organizacional sobre competências faz referência, contribuindo para uma melhor compreensão da atuação destes atores sociais.

Por este estudo ter sido realizado no contexto da Universidade Aberta do Brasil no lócus da Universidade de Brasília espera-se que o mesmo possa resultar em ações de benchmarking por parte de outras organizações que pretendam implementar eventos ofertados a distância, como ações de capacitação e treinamento, bem como atividades orientadas à gestão de competências. Isso poderá aumentar a qualidade dos serviços prestados e o estímulo à concorrência.

Contudo, como limitações deste estudo, verificou-se a pouca diferenciação profissional dos tutores que participaram das entrevistas e grupos focais. A maioria deles exercia a função de tutor em um curso apenas (a saber, bacharelado em administração pública), o que pode ter feito que as competências mapeadas dissessem respeito, em sua maioria, à realidade deste curso. Isto, todavia, não necessariamente pode ser considerado como um fator negativo, posto que a análise da literatura sobre comportamento organizacional e psicologia organizacional e do trabalho não demonstrou a prevalência de outros estudos voltados ao objetivo estabelecido neste trabalho, demonstrando, assim, o caráter inovador do mesmo.

Outra limitação foi a de que alguns dos tutores entrevistados não detinham conhecimento da linguagem técnica utilizada para a construção das competências, ou mesmo tinham claro o que era uma competência aplicada em sua realidade de trabalho. Esse fator pode ter dificultado o aprofundamento das competências extraídas, assim como a identificação de outras mais.

Outro fator limitador consistiu na quantidade de participantes da pesquisa, que pode ser considerado relativamente pequeno quando se compara ao total de tutores que desempenham esta função em cursos ofertados na modalidade a distância por todo o País. Isto, entretanto, não significa que os dados aqui apresentados não correspondam a outras realidades na atuação dos tutores. Hipotetizase que as competências mapeadas aqui sejam, inclusive, essenciais ou transversais, e que, portanto, poderiam ser generalizadas a outras realidades não captadas no presente trabalho. Novos estudos empíricos, voltados ao mapeamento de competências técnicas e comportamentais de outros tutores oriundos de outros cursos da própria Universidade Aberta, devem ser realizados. Como o tema é novo, outras contribuições neste sentido podem emergir com maior criticidade e intensidade.

Considera-se que o presente estudo contribui academicamente, por se tratar de um tema atual e relevante em comportamento 
organizacional e psicologia organizacional e do trabalho, especialmente na elaboração e planejamento de cursos ofertados na modalidade a distância considerando-se a importância dos tutores na execução de tais cursos. O presente trabalho traz, portanto, implicações práticas relevantes ao prover competências profissionais mínimas a organizações que queiram, por exemplo, estruturar programas de capacitação de tutores, tornando-os aptos a atuarem em cursos a distância.

Espera-se, também, que a aplicação das teorias relativas ao mapeamento de competências em outros campos práticos fora de seu contexto tipicamente investigado na literatura sobre comportamento organizacional, como na função de tutoria, auxilie na consolidação da literatura teórica e empírica deste campo de saber.

Sugere-se, para estudos futuros, a identificação de variáveis que contribuam diretamente para a aquisição e expressão de competências no âmbito organizacional. Ainda, que se investigue como se dá a disseminação dessas competências internamente, especialmente 0 efeito que as interações sociais têm sobre a transferência destas competências à realidade de trabalho.

Recomenda-se, também, o estudo de como se dá a complexa interrelação entre conhecimentos, habilidades e atitudes formando uma competência, e como a mesma é expressa em termos de desempenho no trabalho. Outras variáveis, de nível de tarefa e contexto, relacionadas, por exemplo, à reação quanto à interface gráfica dos cursos e análise das atitudes dos tutores envolvidos com o ensino a distância, também devem ser consideradas no mapeamento de competências.

Como implicações práticas sugere-se que as atribuições de tutores sejam formalmente planejadas considerando-se o desenvolvimento das competências presentemente mapeadas. Outras competências, ainda mais específicas às tarefas, ainda precisam ser identificadas. Outra sugestão é referente ao desenvolvimento de sistemas de gestão de desempenho de tutores com base nas competências funcionais identificadas. Recomenda-se, também, a implementação de ações de capacitação tanto para os colaboradores quanto gestores, promovendo uma cultura de apoio e suporte ao desenvolvimento de competências no âmbito de cursos a distância.

Sugere-se, ainda, a utilização das competências identificadas nesse estudo para diagnosticar a existência de lacunas ou gap's de aprendizagem, ou seja, discrepâncias entre o que a organização necessita e o repertório atual dos indivíduos. Caso os colaboradores detenham as competências necessárias a uma eficaz execução de suas atribuições e as coloque em prática, o colaborador tenderá a agregar valor à Organização, permitindo que a mesma adquira vantagem competitiva. Se não, ações de capacitação orientadas à aquisição e expressão destas competências se tornam necessárias. 
Conclui-se, em síntese, que o mapeamento de competências realizado nesse estudo poderá ser de grande valia às organizações interessadas em agregarem valor às suas ações instrucionais desenvolvidas na modalidade à distância, tornando-se um importante fator para a obtenção de diferencial e vantagem competitiva. O avanço nas discussões teóricas e empíricas na literatura de comportamento organizacional sobre mapeamento e gestão por competências também é um ponto importante deste trabalho a ser ressaltado. A aplicação do mapeamento de competências de tutores tende a contribuir para o avanço teórico e prático em psicologia organizacional e do trabalho, principalmente no que concerne à sua consolidação como um campo de saber capaz de prover ferramentas e instrumental orientados à análise do contexto organizacional, garantindo, assim, a busca por sua efetividade na gestão.

\section{Referências}

BAHRY, C.P.; TOLFO, S.R. A Gestão de Competências e a Obtenção de Vantagem Competitiva Sustentável em Organizações Bancárias. Revista de Administração Mackenzie, São Paulo, v. 5, n. 2, p. 3754, 2004.

BARBOSA, A. C. Q.; RODRIGUES, M. A. Um olhar sobre os modelos de gestão de competências adotados por grandes empresas brasileiras. In: ENCONTRO DA ASSOCIAÇÃO NACIONAL DOS PROGRAMAS DE PÓS-GRADUAÇÃO EM ADMINISTRAÇÃO, 2005, Brasília. Anais do XXIX Encontro da Associação Nacional dos Programas de Pós-Graduação em Administração. Brasília, 2005. BARDIN, L. Análise de conteúdo. Lisboa: Edições 70, 2009.

BOYATZIS, R. E. The competent management: a model for effective performance. New York: J ohn Wiley, 1982.

BRANDÃO, H. P. Competências no trabalho: uma análise da produção científica brasileira. Estudos de Psicologia, Natal, v. 12, n. 2, p. 149-158, 2007.

BRANDÃO, H. P.; BAHRY, C. P. Gestão por competências: métodos e técnicas para mapeamento de competências. Revista do Serviço Público, Brasília, v. 56, n. 2, p. 179-194, 2005.

BRANDÃO, H. P.; BORGES-ANDRADE, J. Causas e efeitos da expressão de competências no trabalho: para entender melhor a noção de competência. Revista de Administração Mackenzie, São Paulo, v. 8, n. 3, p. 32-49, 2007.

DUTRA, J. S. Competências: conceitos e instrumentos para a gestão de pessoas na empresa moderna. São Paulo: Atlas, 2004.

DUTRA, J. S. Gestão de pessoas: modelo, processos, tendências e perspectivas. São Paulo: Atlas, 2006. 
FLEURY, A; FLEURY, M. T. Estratégias empresariais e formação de competências. São Paulo: Atlas, 2001.

GUIMARÃES, T. A; BRUNO-FARIA, M. F; BRANDÃO, H. P. Aspectos metodológicos do diagnóstico de competências em organizações. In Borges-Andrade, J. E.; Abbad, G. S; Mourão, L. (Orgs). Treinamento, desenvolvimento e educação em organizações e trabalho: fundamentos para a gestão de pessoas. Porto Alegre: Artmed, 2006.

LE BOTERF, G. Desenvolvendo a competência dos profissionais. Porto Alegre: Artmed, 2003.

MCCLELLAND, D. C. Testing for Competence rather than Intelligence. American Psychologist, New York , v. 28, n. 1, p. 1-14, 1973.

PAIVA, K. C. M.; MELO, M. C. O. L. Competências, Gestão de Competências e Profissões: perspectivas de pesquisas. Revista de Administração Contemporânea, Rio de Janeiro, v. 12, n.2, 2008.

SANTOS, F. A.S., COELHO Jr., F.A.; FAIAD, C. Análise Crítica da Produção Cientifica Brasileira sobre Competências em Periódicos da Área de Administração entre 2005 e 2010. In ENCONTRO DA ASSOCIAÇÃO NACIONAL DOS PROGRAMAS DE PÓS-GRADUAÇÃO EM ADMINISTRAÇÃO, 2011, Brasília. Anais do XXXV Encontro da Associação Nacional dos Programas de Pós-Graduação em Administração. Brasília, 2011.

SPENCER JR, L.M.; SPENCER, S.M. Competence at work: models for superior performance. New York: John Wiley, 1993.

\section{Endereço para correspondência \\ Francisco Antonio Coelho J unior}

Universidade de Brasília. Faculdade de Faculdade de Economia, Administração, Contabilidade e Ciência da Informação e Documentação. Campus Universitário Darcy Ribeiro.

Programa de Pós-Graduação em Administração (PPGA), PPGA - Instituto Central de Ciências, Ala Norte, Subsolo, Módulo 25, CEP 70910-900. Brasília-DF, Brasil.

Endereço eletrônico: fercoepsi@yahoo.com.br, acoelho@unb.br

\section{Cristiane Faiad}

Universidade Salgado de Oliveira. Programa de Mestrado em Psicologia. Rua Marechal Deodoro, 263, Centro, Niterói, CEP 24030-060. Niterói-RJ, Brasil. Endereço eletrônico: crisfaiad@gmail.com

\section{J oão Paulo Fonseca Borges}

Universidade de Brasília. Faculdade de Faculdade de Economia, Administração, Contabilidade e Ciência da Informação e Documentação. Campus Universitário Darcy Ribeiro.

Programa de Pós-Graduação em Administração (PPGA), PPGA - Instituto Central de Ciências, Ala Norte, Subsolo, Módulo 25, CEP 70910-900. Brasília-DF, Brasil.

Endereço eletrônico: joaopaulofb@gmail.com

\section{Natália Ferreira da Rocha}

Universidade de Brasília. Faculdade de Faculdade de Economia, Administração, Contabilidade e Ciência da Informação e Documentação. Campus Universitário Darcy Ribeiro.

Programa de Pós-Graduação em Administração (PPGA), PPGA - Instituto Central de Ciências, Ala Norte, Subsolo, Módulo 25, CEP 70910-900. Brasília-DF, Brasil. 
Francisco Antonio Coelho J unior, Cristiane Faiad, J oão Paulo Fonseca Borges, Natália Ferreira da Rocha Mapeamento de competências profissionais de Tutores de cursos na Modalidade à Distância

Endereço eletrônico: nataliafr29@gmail.com

Recebido em: 28/09/2011

Reformulado em: 28/08/2012

Aceito para publicação em: 20/09/2012

Acompanhamento do processo editorial: Deise Mancebo

\section{Notas}

* Professor Adjunto do Departamento de Administração da UnB e Professor do Programa de Pós-Graduação em Administração da UnB; Doutor em Psicologia Social, do Trabalho e Organizacional pelo Programa de Psicologia Social, do Trabalho e Organizacional.

** Doutora em Psicologia Social, do Trabalho e Organizacional pelo Programa de Psicologia Social, do Trabalho e Organizacional da Universidade de Brasília, Professora Titular do Programa de Mestrado em Psicologia da Universidade Salgado de Oliveira.

*** Graduando do Curso de Administração de Empresas da Universidade de Brasília-UnB.

**** Graduanda do Curso de Administração de Empresas da Universidade de Brasília-UnB. 